\title{
Screening blood-fed mosquitoes for the diagnosis of filarioid helminths and avian malaria
}

\author{
Carina Zittra', Zsanett Kocziha², Szilárd Pinnyei ${ }^{3}$, Josef Harl ${ }^{1}$, Katrin Kieser ${ }^{1}$, Alice Laciny ${ }^{1}$, Barbara Eigner ${ }^{1}$, \\ Katja Silbermayr ${ }^{1}$, Georg G Duscher ${ }^{1}$, Éva Fok ${ }^{2^{*}}$ and Hans-Peter Fuehrer ${ }^{1 *}$
}

\begin{abstract}
Background: Both Dirofilaria repens and recently D. immitis are known to be endemic in Hungary. As one of several recent cases, the fatal case of a dog infested with D. immitis in Szeged, Southern Hungary, received attention from the media. Hence it was decided to catch mosquitoes in the garden where the dog lived to screen for filarioid helminths and Plasmodium spp. using molecular tools.

Methods: Mosquitoes were caught in Szeged, in the garden where the infected dog was kept, in July 2013 with M-360 electric mosquito traps and were stored in ethanol until further procedure. Female mosquitoes were classified to genus level by morphology. Each mosquito was homogenized and analyzed for filarioid helminths and avian malaria using standardized PCR techniques. Positive mosquito samples were further identified to species level by comparing a section of the mitochondrial COl gene to GenBank ${ }^{\circledR}$ entries.

Results: In this study, 267 blood-fed mosquitoes were caught in July 2013 in Szeged. Subsequent molecular screening revealed that not only D. immitis was present in the analyzed specimens but also DNA of D. repens, Setaria tundra and Plasmodium spp. was confirmed.

Conclusions: The analysis of blood-fed mosquitoes for the diagnosis of Dirofilaria spp. and other mosquito-borne pathogens seems to be an adequate technique to evaluate if filarioid helminths are present in a certain area. Usually only unfed female mosquitoes are analyzed for epidemiological studies. However, blood-fed mosquitoes can only be used for screening if a pathogen is present because the role of the mosquito as vector cannot be classified (blood of bitten host). Furthermore, Setaria tundra was confirmed for the first time in Hungary.
\end{abstract}

Keywords: Culicidae, Dirofilaria, Setaria tundra, Blood-fed, Avian malaria, Cytochrome c oxidase I, Cytochrome b, Hungary

\section{Background}

The city of Szeged is situated in the Southern Great Hungarian Plain, near the mouth of the River Maros and the lower reaches of the River Tisza. The natural mosquito density in this area is mainly influenced by prevailing rainfall and the flood of the River Tisza, which has two maxima annually, occurring in April after snowmelt and at the end of November. As a wetland, this region is known to provide many breeding habitats for mosquitoes (Diptera: Culicidae) [1]. Species belonging to the genera

\footnotetext{
*Correspondence: Fok.Eva@aotk.szie.hu; hans-peter.fuehrer@vetmeduni.ac.at ${ }^{2}$ Department of Parasitology and Zoology, Faculty of Veterinary Science, Szent István University, Budapest, Hungary

'Institute of Parasitology, Department of Pathobiology, University of Veterinary Medicine, Vienna, Austria

Full list of author information is available at the end of the article
}

Culex, Culiseta, Aedes, Anopheles, and Coquillettidia have been mentioned as being incriminated in the transmission cycle of filarioidal infections [2].

Both $D$. repens and $D$. immitis are emerging causative agents of parasitic zoonoses in Europe occurring in domestic and wild carnivores and are transmitted by mosquitoes [3]. Mostly climatic changes are considered to be the main reason for the expansion of geographic ranges in parasites [3] and also influence the development and longevity of their hosts; both the hosts and parasites are currently expanding to northern areas in Europe. These findings were underlined by an increasing number of diagnosed filarioid infections in countries such as Austria, Germany, the United Kingdom, the Netherlands, Sweden, and Hungary [2]. Further global drivers like trade, travel (movement of dogs across Europe), and insecticide 
resistance are also mentioned as being responsible for a higher risk of animal and human infections [3].

In Hungary imported dogs infected with $D$. immitis, the most frequent causative agent of canine and feline cardiopulmonary filarioidosis, were already reported in 1982 [4]. However, the first autochthonous case of a $D$. immitis infection in a dog, originating from Jász-Nagykun-Szolnok, was reported in 2007 [5]. Since that time, Hungary is considered to be a heartworm endemic country and autochthonous filarioid infections caused by $D$. immitis have since been examined in Hungarian red foxes (Vulpes vulpes) and golden jackals (Canis aureus) [6]. In contrast, cases of filarioid infections caused by $D$. repens, the causative agent of canine and feline subcutaneous and ocular filarioidosis, were not reported until 1997 [7]. It was not clear that the latter infection was really acquired in Hungary [8], so the first autochthonous cases of $D$. repens infection were reported in 1998 and 1999 [9,10].

The primarily boreal filarioid parasite Setaria tundra is the causative agent of setariosis and can act as a significant pathogen in domestic reindeer (Rangifer tarandus), but also in roe deer (Capreolus capreolus), moose (Alces alces), and other cervids $[11,12]$. S. tundra is known to be endemic in Central Europe (e.g. Germany and Austria), with roe deer as the main vertebrate host [13]. In Hungary, only S. equina has been reported in horses (Equus ferus caballus) [14] and S. cervi in red deer (Cervus elaphus) [15]. However, $S$. tundra had never been reported from Hungary until now. Main vectors are mosquitoes belonging to the genera Aedes, Anopheles and Ochlerotatus [13], of which Aedes spp. are considered the most important and competent vectors. In Finland, S. tundra caused severe outbreaks of peritonitis, with significant economic losses in semidomestic reindeer in 1973 and 2003-2005 [16]. However, human infections have not been described so far.

In principle, the known main vectors of $D$. immits, $D$. repens, and $S$. tundra are mosquito species belonging to the genera Aedes, Anopheles, Ochlerotatus, and Culex $[16,13]$. Mosquitoes are distributed worldwide with over 3,500 species. Fifty mosquito species belonging to eight genera (Anopheles, Aedes, Ochlerotatus, Coquillettidia, Culex, Culiseta, Orthopodomyia, and Uranotaenia) have been documented in Hungary to date [17]. The presence of 17 mosquito species in Szeged, belonging to the genera Culex, Aedes, Ochlerotatus, Culiseta, and Anopheles, was reported in 2006 [1] and underlines the importance of fast and efficient screening methods in order to gain an overview of the present infestation rate and further spread of filarioid helminths in this country.

As one of several recent cases, the fatal case of a dog infested with $D$. immitis in Szeged, Southern Hungary, received attention from the media and served as the initial reason to perform this study. The main aim of this study was the examination of the usefulness of screening blood-fed mosquitoes for the presence of filarioid helminths and avian malaria.

\section{Methods}

Mosquitoes were caught in July 2013 with an M-360 electric mosquito trap in Szeged, Southern Hungary. They were stored in $75 \%$ ethanol until further processing and were transported to the Institute of Parasitology at the University of Veterinary Medicine, Vienna. Due to the sampling method, female mosquitoes were only classified to the genus level by morphological standard characteristics using the keys by Schaffner et al. [18] and Becker et al. [19]. Treating each mosquito individually and not merging them into pools, is obligatory to define an accurate estimation of the real number of mosquitoes positive for filarioid helminths and/or avian malaria. Therefore, a 3-mm Tungsten Carbide Bead (Qiagen, Hilden, Germany) was added to each mosquito. After homogenization in a TyssueLyser II (Qiagen, Hilden, Germany), DNA was extracted using the DNeasy ${ }^{\circ}$ blood and tissue isolation kit according to the manufacturer's protocol. Afterwards the mosquitoes were analyzed for filarioid helminths by a conventional polymerase chain reaction (PCR), targeting an approximately $667 \mathrm{bp}$ fragment of the filarioid mitochondrial cytochrome oxidase subunit I gene (COI) as reported previously [13,20,21].

In order to examine the presence of avian malaria, a nested PCR, targeting an approximately 500 bp fragment of the mitochondrial cytochrome $b$ gene $(c y t b)$, was used [22,23].

Furthermore, PCR products positive for filarioid helminths or avian malaria were excised from the gel using the QIAquick ${ }^{\circ}$ Gel Extraction Kit (Qiagen, Hilden, Germany) or were purified using Illustra ${ }^{\mathrm{mw}}$ ExoStar $^{\mathrm{mw}} 1$-Step, an enzymatic PCR and Sequencing Clean-up (GE Healthcare, Buckinghamshire, United Kingdom), for subsequent DNA sequencing. Afterwards consensus sequences were compared to GenBank ${ }^{\circ}$ entries using BLAST (http://blast.ncbi. nlm.nih.gov). Mosquitoes that were positive for filarioid helminths and avian malaria were further specified to species level by barcoding (COI gene) as described previously [24].

In order to demonstrate the high genetic diversity of avian Plasmodium found at the Hungarian investigation site, a phylogenetic tree was calculated with avian malaria sequences retrieved from the NCBI database (http:// www.ncbi.nlm.nih.gov/). A BLAST-search limited to the genus Plasmodium (taxid:5820) was performed against the NCBI nucleotide database with one of the cytb sequences obtained in the present study. The search resulted in a total of 3,824 BLAST hits. In order to obtain only those fragments overlapping with the $c y t b$ fragment analyzed, the BLAST hits were downloaded as aligned sequences in FASTA format. The GenBank ${ }^{\circ}$ files were 
downloaded in addition to extract specific metadata (organism, country and host). The two files were then merged in Microsoft Excel, and all 650 BLAST hits with less than $400 \mathrm{bp}$ were excluded from the dataset, resulting in a total of 3,175 sequences. The information on the host species was either retrieved from the GenBank ${ }^{\circ}$ files or from the original publication, respectively; a total of 988 sequences originated from blood samples of bird hosts, 65 of which were excluded from the alignment due to the presence of ambiguous characters and/or stop codons. Including the 16 Hungarian samples, the alignment contained a total of 939 sequences. The sequences were aligned with Mafft v.7 [25], using the setting G-INS-i for accurate alignments. Using the program DAMBE v.5.2.78 [26], sequences were collapsed to 419 unique haplotypes, which were subsequently used for the phylogenetic tree calculation. A search for the best fitting substitution model was performed with JModeltest v.2.1.5 [27]. Based on the Akaike Information Criterion (AIC), TN93 + G was the best model. Finally, a Neighbor-Joining tree was calculated with 500 bootstrap replicates using MEGA v.6.06 [28].

\section{Results}

In this study 267 blood-fed mosquitoes were caught with the M-360 electronic mosquito trap in Szeged, Southern Hungary in June 2013. The molecular screening revealed that not only $D$. immitis was present in the analyzed specimens. DNA of D. repens, S. tundra, and Plasmodium spp. was also confirmed. In total, 22 mosquitoes $(8.2 \%$ of the total catch) were positive; four Cx. pipiens (Linnaeus 1785), one $C x$. modestus (Ficalbi 1889), and one Oc. caspius (Pallas 1771) were positive for $D$. immitis. D. repens was detected in one Oc. caspius (Table 1). The finding in a single Ae. vexans (Meigen 1830) infected with $S$. tundra represents the first record of DNA of this parasite in Hungary. Additionally, avian malaria was detected in 16 specimens of Cx. pipiens (Table 2).

A Neighbor-Joining tree was calculated with 923 avian malaria $c y t b$ sequences from the NCBI database and the 16 Plasmodium sequences of the present study. The aim was to show the high genetic diversity of Plasmodium samples analyzed in the present study. The tree is displayed as an unrooted radial tree (Figure 1). Due to the high number of sequences and the short sequence length (400 bp), support values were low for most nodes and are not displayed in the tree. The 11 Hungarian Plasmodium haplotypes (11 haplotypes) cluster in four of the main clades in the tree. Other sequences in the respective clades originate from bird blood samples collected worldwide. The data show none of the Hungarian Plasmodium variants is unique to Europe, but that all haplotypes, respectively slightly deviating ones, are also present in other continents.

\section{Discussion}

The analysis of blood-fed mosquitoes for the diagnosis of Dirofilaria spp. and other mosquito-borne pathogens seems to be an adequate technique to evaluate if parasites such as filarioid helminths are present in a certain area. Usually only unfed female mosquitoes are analyzed for epidemiological studies, because attracting female blood-fed mosquitoes is still problematic. Most sampling methods are based on the usage of carbon dioxide or lures imitating the human skin and similar attractants. These methods attract mainly unfed female mosquitoes searching for an adequate potential host. In contrast, blood-fed females seek resting places or are attracted by potential breeding sites. In this case the presence of a rain barrel, situated in the garden of the infected dog, might be the main reason for the high number of sampled blood-fed females.

Another important issue to be considered is that bloodfed mosquitoes can only be used for screening if a pathogen is present, whereas the role of the mosquito as a vector cannot be classified. The possibility of screening the blood of the bitten host is given by this method, because female mosquitoes take up microfilaria by feeding on infected animals, but the further development into the infecting stage L3 strongly depends on the vector efficiency and competence of the intermediate host, the mosquito [29]. Furthermore the development of the microfilaria within the mosquito itself is temperature-dependent,

Table 1 Filarioid helminths detected in blood-fed mosquitoes

\begin{tabular}{lllll}
\hline Sample & Intermediate host/Mosquito & GenBank $^{\circledR}$ entry & Pathogen & GenBank entry $^{\circledR}$ \\
\hline HU11 & Culex (Culex) pipiens & KM452929 & Dirofilaria immitis & KM452920 \\
HU73 & Ochlerotatus (Ochlerotatus) caspius & KM452934 & Dirofilaria immitis & KM452921 \\
HU91 & Aedes (Aedimorphus) vexans & KM452935 & Setaria tundra & KM452922 \\
HU151 & Culex (Culex) pipiens & KM452937 & Dirofilaria immitis & KM452923 \\
HU201 & Culex (Culex) pipiens & KM452943 & Dirofilaria immitis & KM452924 \\
HU217 & Culex (Culex) pipiens & KM452945 & Dirofilaria immitis & KM452925 \\
HU236 & Culex (Barraudius) modestus & KM452947 & Dirofilaria immitis & KM452926 \\
HU250 & Ochlerotatus (Ochlerotatus) caspius & KM452948 & Dirofilaria repens & KM452927 \\
\hline
\end{tabular}


Table 2 Mosquitoes infested with Plasmodium spp. (cytb gene)

\begin{tabular}{|c|c|c|c|c|}
\hline Sample & Host/Mosquito & GenBank entry & Pathogen & GenBank entry \\
\hline $\mathrm{HU} 5 \mathrm{~A}$ & Culex (Culex) pipiens & KM452928 & Plasmodium sp. & KM396866 \\
\hline HU5B & Culex (Culex) pipiens & KM452928 & Plasmodium sp. & KM396867 \\
\hline $\mathrm{HU} 29$ & Culex (Culex) pipiens & KM452930 & Plasmodium sp. & KM396868 \\
\hline HU36 & Culex (Culex) pipiens & KM452931 & Plasmodium sp. & KM396869 \\
\hline $\mathrm{HU} 42$ & Culex (Culex) pipiens & KM452932 & Plasmodium sp. & KM396870 \\
\hline HU63 & Culex (Culex) pipiens & KM452933 & Plasmodium sp. & KM396871 \\
\hline HU128 & Culex (Culex) pipiens & KM452936 & Plasmodium sp. & KM396872 \\
\hline HU157 & Culex (Culex) pipiens & KM452938 & Plasmodium sp. & KM396873 \\
\hline HU172 & Culex (Culex) pipiens & KM452939 & Plasmodium sp. & KM396874 \\
\hline HU184 & Culex (Culex) pipiens & KM452940 & Plasmodium sp. & KM396875 \\
\hline HU185 & Culex (Culex) pipiens & KM452941 & Plasmodium sp. & KM396876 \\
\hline HU196 & Culex (Culex) pipiens & KM452942 & Plasmodium sp. & KM396877 \\
\hline HU210 & Culex (Culex) pipiens & KM452944 & Plasmodium sp. & KM396878 \\
\hline $\mathrm{HU} 220 \mathrm{~A}$ & Culex (Culex) pipiens & KM452946 & Plasmodium sp. & KM396879 \\
\hline HU220B & Culex (Culex) pipiens & KM452946 & Plasmodium sp. & KM396880 \\
\hline HU252 & Culex (Culex) pipiens & KM452949 & Plasmodium sp. & KM396881 \\
\hline
\end{tabular}

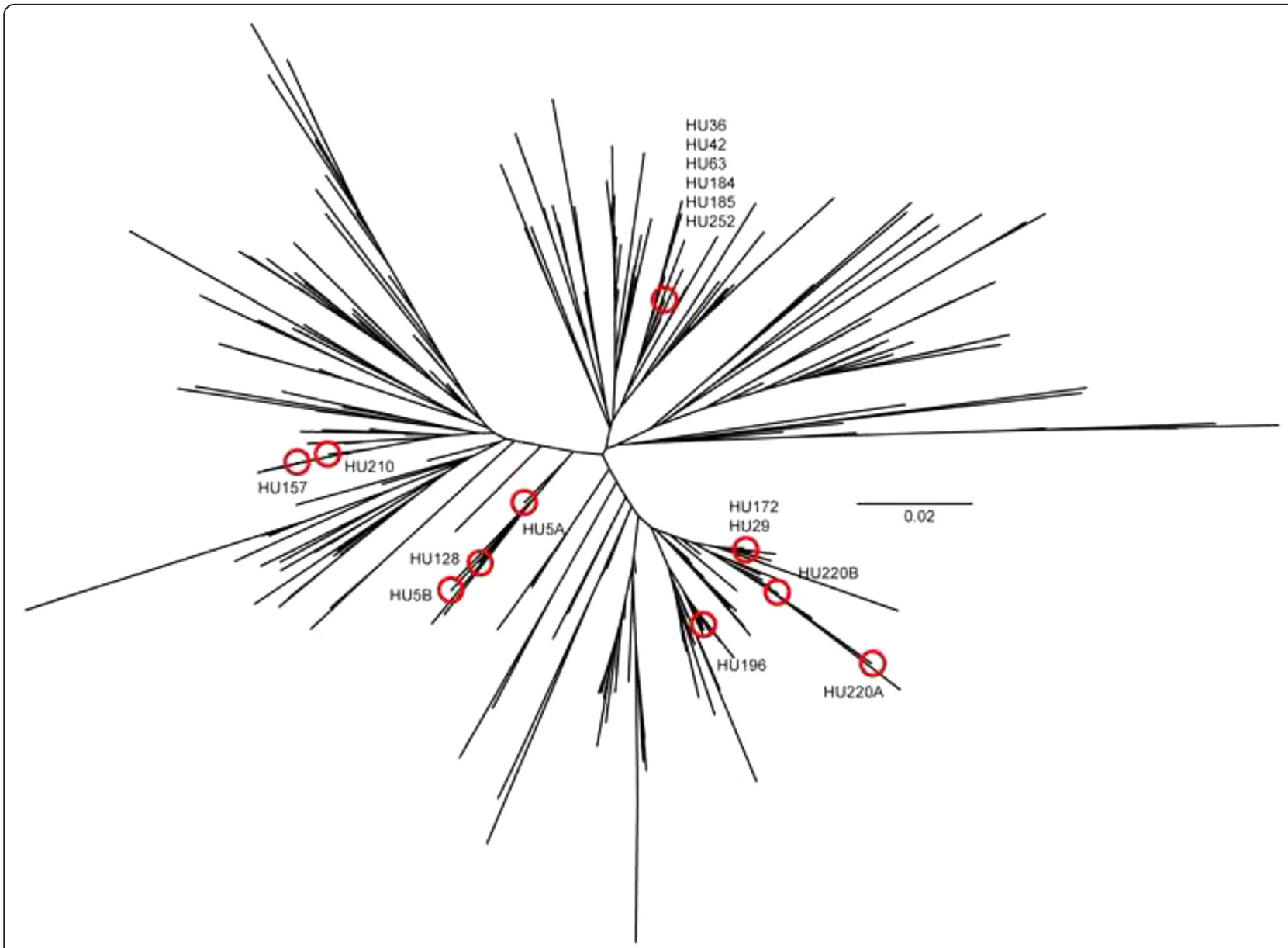

Figure 1 Unrooted radial neighbour-joining tree. Plasmodium cytb sequences of the present study and worldwide avian malaria sequences. Red circles mark tips of Hungarian Plasmodium lineages. 
requiring about two weeks at a temperature of $\geq 26^{\circ} \mathrm{C}$ [29]. The longevity, seasonal appearance, and distribution of the individual mosquito depend on the mosquito species itself and on the prevailing climate [30].

The abundance of $D$. repens infections has increased since the first detection of $D$. repens in Hungary, especially in wet areas along the Danube and the River Tisza [31]. Though the mosquito collections can differ between natural and urban areas, Szeged, as a city, provides many potential breeding habitats like artificial and natural lakes, rain barrels and similar artificial water containers near houses, and rubbish dumps, which can easily be found by species belonging to the genus Culex. In contrast to Aedes and Ochlerotatus, numbers of Culex individuals can be considerably high even in seasons with a low amount of precipitation [1]. A previous study of mosquito collections observed Culex pipiens molestus and Culex modestus as the most prevalent mosquito species in Szeged [1]. In our study, $86.4 \%$ of mosquitoes infected with filarioid helminths and avian malaria belonged to the genus Culex (Tables 1 and 2). Thus, the vector competence of Culex species and the possibility to breed several generations per year, independent of precipitation and floods of the River Tisza, should be monitored.

\section{Conclusions}

The molecular screening of blood-fed mosquitoes for filarioid helminths is an adequate tool to confirm the presence of Dirofilaria spp. and Plasmodium spp. This screening method supports a fast diagnosis of Dirofilaria and other pathogens and is necessary considering that climate change and globalization increase the risk of zoonotic D. immitis and D. repens in Central and Northern Europe [32]. Furthermore, DNA of $S$. tundra was confirmed for the first time in Hungary. Suitable studies on the distribution of $S$. tundra in Central Europe remain scarce and the possible health impact on the endemic cervid fauna in Hungary needs further epidemiological investigation.

\section{Abbreviations}

COI: Cytochrome c oxidase subunit l; Cytb: Cytochrome b.

\section{Competing interests}

The authors declare that they have no competing interests.

\section{Authors' contributions}

$\mathrm{CZ}$ and HPF performed the mosquito identification and compiled the results for the manuscript. ZK and SP collected the mosquito specimens in the field. $C Z, B E, K K, A L$, and HPF performed the molecular work (sample preparation, DNA extraction, PCRs, and sequencing). JH performed the sequence analysis. KS and GGD provided scientific assistance and were responsible for the implementation of the research project; ÉF initiated and designed the research project. HPF realized and coordinated the research project at the institute, supervised the laboratory work, and edited the manuscript. All authors read and approved the final manuscript.

\section{Acknowledgements}

Parts of this research (Hans-Peter Fuehrer and Carina Zittra) were funded by the ERA-Net BiodivERsA, with the national funders FWF I-1437, ANR-13-EBID0007-01 and DFG BiodivERsA KL 2087/6-1 as part of the 2012-13 BiodivERsA call for research proposals.

\section{Author details}

'Institute of Parasitology, Department of Pathobiology, University of Veterinary Medicine, Vienna, Austria. ${ }^{2}$ Department of Parasitology and Zoology, Faculty of Veterinary Science, Szent István University, Budapest, Hungary. ${ }^{3}$ Institute of Animal Sciences and Wildlife Management, Faculty of Agriculture, Szeged University, Hódmezővásárhely, Hungary.

Received: 5 November 2014 Accepted: 2 January 2015

Published online: 13 January 2015

\section{References}

1. Szepesszentgyörgyi Á, Rentsendorj O. Seasonal changes in the mosquito fauna (Diptera, Culicidae) in the city of Szeged in 1999. Tiscia. 2006;35:33-9.

2. Mas-Coma S, Valero MA, Bargues MD. Effects of climate change on animal and zoonotic helminthiases. Rev Sci Tech Of Int Epiz. 2008;27:443-52.

3. Genchi C, Kramer LH, Rivasi F. Dirofilarial infections in Europe. Vector Borne Zoonotic Dis. 2011;11:1307-17.

4. Boros $\mathrm{G}$, Janisch M, Sebestyén G. Dirofilaria immitis fertőzöttség kutyában [Dirofilaria immitis infestation in dogs]. Magyar Áo Lapja. 1982;37:313-6.

5. Jacsó O, Mándoki M, Majoros G, Pétsch M, Mortarino M, Genchi C, et al. First autochthonous Dirofilaria immitis (Leidy, 1856) infection in a dog in Hungary. Helminthologia. 2009;46:159-61.

6. Tolnai Z, Széll Z, Sproch A, Szeredi L, Sréter T. Dirofilaria immitis: an emerging parasite in dogs, red foxes and golden jackals in Hungary. Vet Parasitol. 2014:203:339-42.

7. Zahler M, Glaser B, Gothe R. Eingeschleppte Parasiten bei Hunden: Dirofilaria repens und Dipetalonema reconditum. Tierarztl Prax. 1997;25:388-92.

8. Fok É.The importance of dirofilariosis in carnivores and humans in Hungary, past and present. In Dirofilaria immitis and D. repens in dog and cat and human infections. Edited by Genchi C, Rinaldi L, Cringoli G. Napoli: Rolando Editore; 2007:181-188.

9. Fok É, Szaboó Z, Farkas R. Dirofilaria repens fertőzöttség elso" hazai diagnosztizálása kutyában sebészeti beavatkozás során. TThe first autochthonous case of a dog infected with Dirofilaria repens in Hungary]. Kisállatorvoslás. 1998:4:218-9.

10. Széll Z, Sréter T, Csikós K, Kátai Z, Dobos-Kovács M, Vetési F, et al. Autochton Dirofilaria repens fertőzöttség kutyákban. [Autochtonous Dirofilaria repens infection in dogs]. Magyar Áo Lapja. 1999;121:100-4.

11. Laaksonen S, Pusenius J, Kumpula J, Venäläinen A, Kortet R, Oksanen A, et al. Climate change promotes the emergence of serious disease outbreaks of filarioid nematodes. EcoHealth. 2010;7:7-13.

12. Laaksonen S, Kuusela J, Nikander S, Nylund M, Oksanen A. Outbreak of parasitic peritonitis in reindeer in Finland. Vet Rec. 2007;160:835-41.

13. Czajka C, Becker N, Poppert S, Jost H, Schmidt-Chanasit J, Krueger A Molecular detection of Setaria tundra (Nematoda: Filarioidea) and an unidentified filarial species in mosquitoes in Germany. Parasit Vectors. 2012;5:14.

14. Hornok S, Genchi C, Bazzocchi C, Fok É, Farkas R. Prevalence of Setaria eqina microfilaraemia in horses in Hungary. Vet Rec. 2007;161:814-6.

15. Sugár L, Kovácz S, Kovács A. Subdural occurrence of Elaphostrongyluscervi and Setariacervi in red deer of West Hungary. In: Advances in deer biology. Prague, Czech Republic: 6th International Deer Biology Congress; 2006.

16. Laaksonen S, Solismaa M, Kortet R, Kuusela J, Oksanen A. Vector transmission dynamics for Setaria tundra (Filarioidea: Onchocercidae), a parasite of reindeer in Finland. Parasit Vectors. 2009;2:3.

17. Kenyeres Z, Tóth S. Landscape-structure determined mosquito diversity in Hungary (Central Europe). J Mosq Res. 2012;5:32-8.

18. Schaffner F, Angel G, Geoffroy B, Hervy JP, Rhaiem A, Brunhes J. The Mosquitoes of Europe (CD-ROM). Montpellier, France: IRD Éditions \& EID Méditerrannée; 2001

19. Becker N, Pedrić D, Zgomba M, Boase C, Madon M, Dahl C, et al. Mosquitoes and their control. Berlin: Springer; 2010.

20. Silbermayr K, Eigner B, Joachim A, Duscher GG, Seidel B, Allerberger F, et al. Autochthonous Dirofilaria repens in Austria. Parasit Vectors. 2014;7:226. 
21. Abigail C, Chiang LP, Hapuarachchi HC, Tan CH, Pang SC, Lee R, et al. DNA barcoding: Complementing morphological identification of mosquito species in Singapore. Parasit Vectors. 2014;7:569.

22. Hellgren $\mathrm{O}$, Waldenström J, Bensch S. A new PCR assay for simultaneous studies of Leucocytozoon, Plasmodium, and Haemoproteus from avian blood. J Parasitol. 2004;90:797-802.

23. Seidel B, Silbermayr K, Kolodziejek J, Indra A, Nowotny N, Allerberger F. Detection of Plasmodium sp.-infested Anopheles hyrcanus (Pallas 1771) (Diptera: Culicidae) in Austria, 2012. Wien Klini Wochenschr. 2013;125:139-43.

24. Kumar NP, Rajavel AR, Natarajan R, Jambulingam P. DNA barcodes can distinguish species of Indian mosquitoes (Diptera: Culicidae). J Med Entomol. 2007:44:1-7.

25. Katoh K, Standley DM. MAFFT Multiple Sequence Alignment Software Version 7: Improvements in Performance and Usability. Mol Biol Evol. 2013;30(4):772-80.

26. Xia X, Xie Z. DAMBE: Data analysis in molecular biology and evolution. J Hered. 2001:92:371-3.

27. Darriba D, Taboada GL, Doallo R, Posada D. jModelTest 2: more models, new heuristics and parallel computing. Nat Meth. 2012;9:772.

28. Tamura K, Peterson D, Peterson N, Stecher G, Nei M, Kumar S. MEGA5: molecular evolutionary genetics analysis using maximum likelihood, evolutionary distance, and maximum parsimony methods. Mol Biol Evol. 2011;10:2731-9.

29. Manfredi MT, Di Cerbo A, Genchi M. Biology of filarial worms parasitizing in dogs and cats. In Dirofilaria immitis and D. repens in dog and cat and human infections. Edited by Genchi C, Rinaldi L, Cringoli G. Napoli: Rolando Editore; 2007:39-46.

30. Cancrini G, Gabrielli S. Vectors of Dirofilaria nematodes: biology behaviour and host/parasites relationships. In Dirofilaria immitis and D. repens in dog and cat and human infections. Edited by Genchi C, Rinaldi L, Cringoli G. Napoli: Rolando Editore; 2007:49-58.

31. Fok É, Kiss G, Majoros G, Jacsó O, Farkas R, Gyurkovszky M. Preliminary results of an epidemiological survey on dirofilariosis of dogs and cats in Hungary. In Dirofilaria immitis and D. repens in dog and cat and human infections. Edited by Genchi C, Rinaldi L, Cringoli G. Napoli: Rolando Editore; 2007:194-196.

32. Kronefeld M, Kampen H, Sassnau R, Werner D. Molecular detection of Dirofilaria immitis, Dirofilaria repens and Setaria tundra in mosquitoes from Germany. Parasit Vectors. 2014;7:30.

\section{Submit your next manuscript to BioMed Central and take full advantage of:}

- Convenient online submission

- Thorough peer review

- No space constraints or color figure charges

- Immediate publication on acceptance

- Inclusion in PubMed, CAS, Scopus and Google Scholar

- Research which is freely available for redistribution 